\title{
Study on mechanical \& thermal properties of PCL blended graphene biocomposites
}

\author{
Dinesh Kumar ${ }^{1}$, Ganesh Babu² and Sai Krishnan ${ }^{3 *}$ (1) \\ ${ }^{1}$ Mechanical Department, Jain University, Bangalore, Karnataka, Índia \\ ${ }^{2}$ Mechatronics Department, Tishk Inernational University, Erbil, Iraqi Kurdistan, Iraq \\ ${ }^{3}$ Mechanical Department, Rajalakshmi Institute of Technology, Chennai, Tamil Nadu, Índia \\ *g.saikrishnan@gmail.com
}

\begin{abstract}
Graphene is a new carbon based nonmaterial that attracts the technology and constitutes one of the great promises for nanotechnology applications in a near feature. It's having versatile intrinsic mechanical, thermal and electrical properties. By Incorporation of small amount of graphene fillers into polymer matrix can create attractive bio composites with different morphological and functional properties. The development of biomaterials with special properties is a requirement in biomedical research, particularly in biomedical application. The aim of this work was to develop biocompatible, usable bio composites for biomedical applications using graphene as filler. Recent research evidenced that grapheme-polymer bio composites are promising materials with applications ranging from transportation, biomedical systems, sensors, electrodes for solar panels and EMI.Chemically converted graphene (CCG) solution were prepared through reduction of $\mathrm{GO}$, and Polycaprolactone ( $\mathrm{PCl})$, a synthetic biodegradable and biocompatible aliphatic polyester also a suitable for developing biocomposites.
\end{abstract}

Keywords: graphene, polymer biocomposites, polycaprolactone, biocompatible.

How to cite: Kumar, D., Babu, G., \& Krishnan, S. (2019). Study on mechanical \& thermal properties of PCL blended graphene biocomposites. Polímeros: Ciência e Tecnologia, 29(2), e2019024. https://doi.org/10.1590/0104-1428.05318

\section{Introduction}

Biodegradable and/or Biocompatible materials have attracted the attention of researchers for many years. With the development of biomedical science, biomaterials have been recognized as an increasingly important area of research. In the biomedical field, a biomaterial can be defined as a material intended to interface with biological systems to evaluate, treat, augment or replace any tissue, organ or function of the body ${ }^{[1]}$. In the past twenty years, significant advancements have occurred in the area of biomaterials. Exhibiting remarkable biodegradability and biocompatibility, biomaterials such as poly(L-lactide) and polycaprolactone have been used extensively in a variety of biomedical applications, namely drug delivery systems, bone fixation devices, vascular grafts, gene delivery systems and tissue engineering ${ }^{[2]}$. In view of the diversity and complexity of the applications, a wide range of biomaterials need to be developed to properly meet the requirements of each particular biomedical application. This requirement is the primary motivation in the development of biocomposites which are usually composed of a biodegradable matrix and a reinforcing filler ${ }^{[3]}$. The structure and properties of the polymers can be optimized by the addition of fillers, and hence a wide range of biomaterials with diverse mechanical and biological properties can be developed. Biodegradable polymers can be categorized in different ways. From a degradation viewpoint, biomaterials can be categorized into two classes, biodegradable and nonbiodegradable.
However, categorizing biopolymers based on their origin into natural and synthetic is the most common way of categorizing those $\mathrm{e}^{[4]}$. Natural biopolymers appear to be the most appropriate option for biomedical applications because of their excellent biocompatibility, their biodegradability through enzymatic or hydrolytic mechanisms and their great ability to copy native cellular environments. However, some fundamental disadvantages of natural biopolymers, namely the possibility of viral infections, antigenicity and variation in properties of different batches, are a major obstacle in fully employing them in biomedical applications ${ }^{[5]}$. Biometrics can also be functioned to meet specific requirements based on their final applications. The functional groups can be introduced either to the monomers or the polymer chains of the polymer. Polysaccharides and proteins are typical natural biopolymers used for biomedical applications ${ }^{[6]}$. Polysaccharides are high molecular weight polymeric carbohydrates composed of one or more monosaccharide repeating units ${ }^{[7]}$. Wide availability, low cost, diversity in structure and the presence of reactive functional groups in the polymer chain are some of the advantages of using polysaccharides for biomedical applications ${ }^{[8,9]}$. Proteins are high molecular weight polymers consisting repeating of units of amino acids linked together via peptide linkages. An attractive property of these natural polymers, polysaccharides in particular, is their great swellability that makes them ideal candidates for developing hydrogels ${ }^{[10,11]}$. 
It should be possible to overcome many of the problems associated with natural polymers and develop materials for specific applications through specific synthesis of polymers. Synthetic materials possess more predictable behavior and batch-to-batch uniformity compared to natural polymers aliphatic polyesters, that are representative of the synthetic biodegradable polymers, are the most commonly used synthetic materials for biomedical applications. Polycaprolactone $(\mathrm{PCl})$ is biodegradable semi-crystalline polyester with some unique properties that make it the material of choice for biomedical fields ${ }^{[12]}$. It has a low melting point $\left(55-60^{\circ} \mathrm{C}\right)$, dissolves in a wide range of organic solvents and is able to form miscible blends with different type of polymers ${ }^{[13]}$. All these properties make it a highly processable material suitable for biomedical applications. Furthermore, it can be easily synthesized from $\varepsilon$ - caprolactone, a relatively inexpensive monomeric unit. There are two approaches to synthesize PCl: the condensation of 6-hydroxycaproic (6-hydroxyhexanoic) acid and the Ring-Opening Polymerization (ROP) of $\varepsilon$-caprolactone ${ }^{[14]}$. ROP is the preferred method as it provides the possibility of synthesizing the polymer with a higher molecular weight and a lower polydispersity ${ }^{[15]} . \mathrm{PCl}$ is extensively investigated in drug delivery applications and numerous micro- and nano-sized drug delivery vehicles are developed from $\mathrm{PCl}^{[16]}$. $\mathrm{PCl}$ shows great compatibility with many organic materials and polymers so it can be used as compatibilizers in many polymer formulations ${ }^{[17,18]}$. A wide range of biomaterials has already been used in developing structures for biomedical applications. However, it is hard to find a polymer that meets all the requirements for developing the perfect material for biomedical applications. As a result, researchers have developed biocomposites that are typically composed of a biodegradable matrix and filler, which is used to compensate for the deficiencies of the matrix ${ }^{[19]}$. Nano-clays, hydroxyapatite and carbonaceous materials are the major fillers that have widely been used in to improve the properties of biomaterials ${ }^{[20,21]}$. Carbonaceous materials such as carbon nanotubes (CNT), fullerenes, graphite, and graphene oxide $(\mathrm{GO})$ and graphene have recently attracted the attention of researchers as composite fillers for biomedical applications. The building block of carbonaceous materials is a layer of sp2 hybridized carbon atoms covalently bonded in a honeycomb lattice known as graphene ${ }^{[22]}$. Carbonaceous materials show excellent electrical, mechanical, and thermal properties that make them ideal fillers to develop materials of high performance for biomedical applications.

\section{Prior Art}

Several studies seek to improve the mechanical properties of biodegradable polymers using hydroxyapatite ${ }^{[23-25]}$, however, the improvements were not large enough to meet the criteria for bone engineering field ${ }^{[26,27]}$. Clay silicates have also been incorporated into polymers to improve their mechanical propertie ${ }^{[28-30]}$, however, it is hard to make a homogenous dispersion from clay silicates as the particles tend to agglomerate inside the polymer matrix due to their highly hydrophilic nature. High conductivity of the graphene attracted the attention of researchers at that time, however, research on graphene moved slowly as synthesis of this nanosheet was found to be experimentally difficult ${ }^{[31]}$. Different approaches were taken to synthesize this 2D carbon structure, including the same methods used for developing CNTs, but none of them were able to prepare a high quality graphene.

Green and Hersam ${ }^{[32]}$ reported the preparation of stable graphene dispersion by using the bile salt sodium cholate. In this work, graphene flakes with controlled thicknesses could be isolated in suspension using density gradient ultracentrifugation (Figure 1). The synthesized graphene dispersion contained monolayer graphene sheets with thicknesses varying between 1 to $>2 \mathrm{~nm}$. However, the graphene concentration of the dispersion was quite low

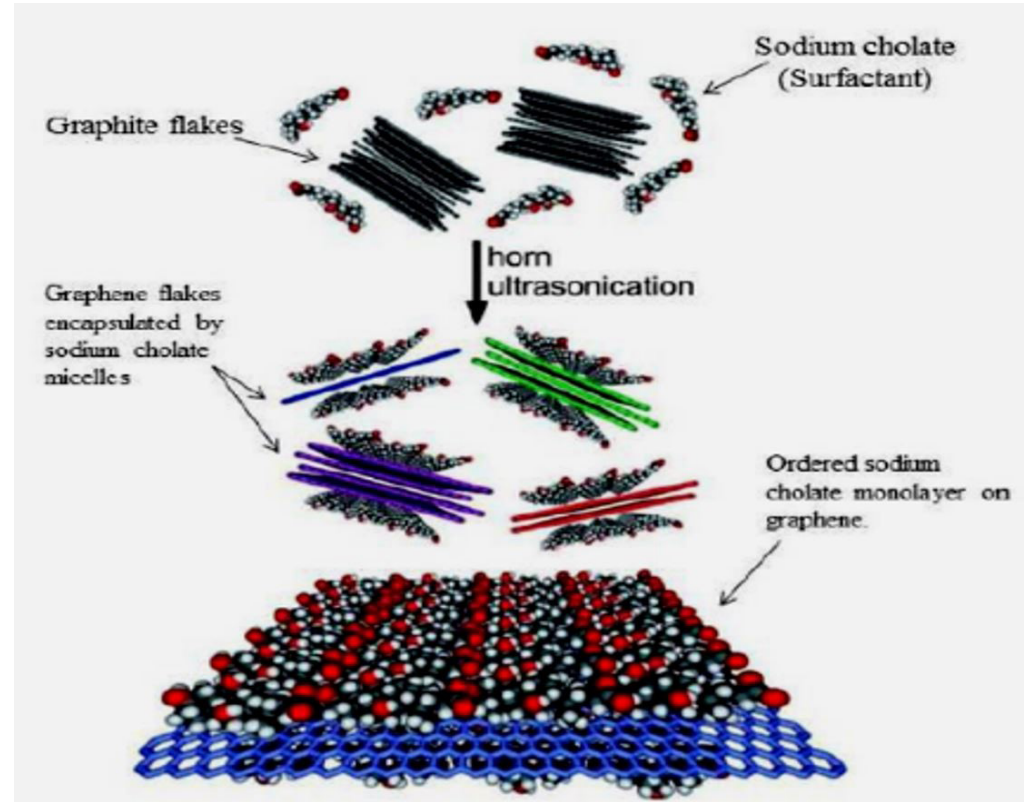

Figure 1. Schematic illustration of the graphene exfoliation process. Combination of graphite and sodium cholate are exfoliated to few-layer graphene. 
$\left(90 \mu \mathrm{g} \mathrm{ml}^{-1}\right)$, making this graphene dispersion an impractical choice for developing composites.

Other metal surfaces such as $\mathrm{Ru}, \mathrm{Ir}, \mathrm{Ni}, \mathrm{Co}$ and $\mathrm{Pt}$ have also been used as substrates for producing graphene layers following the same method. The details are discussed in a review by Wintterlin and Bocquet ${ }^{[33]}$. Lack of control over the graphene thickness and non-uniform growth of single layer graphene ${ }^{[34]}$ are the major issues that limit the real application of CVD method.

Wang et al. ${ }^{[35]}$ prepared PCl-GO composites via in situ polymerization (Figure 2). GO was synthesized following the Hummers method. The tensile strength and elongation at break of the synthesized pure $\mathrm{PCl}$ is reported as $3 \mathrm{MPa}$ and $140 \%$ respectively, and $7 \mathrm{MPa}, 80 \%$ on addition of GO. The improvement in the tensile strength is indicative of the reinforcing effect of the $\mathrm{GO}$ on $\mathrm{PCl}$.

\section{Materials and Methods}

\subsection{Materials}

$\varepsilon$-Caprolactone (97\%), $N, N$-dimethylformamide (DMF), $N, N^{\prime}$-dicyclohexylcarbodiimide (DCC), 4-dimethylaminopyridine (DMAP), 1-Ethyl-3-(3-dimethylaminopropyl) carbodiimide

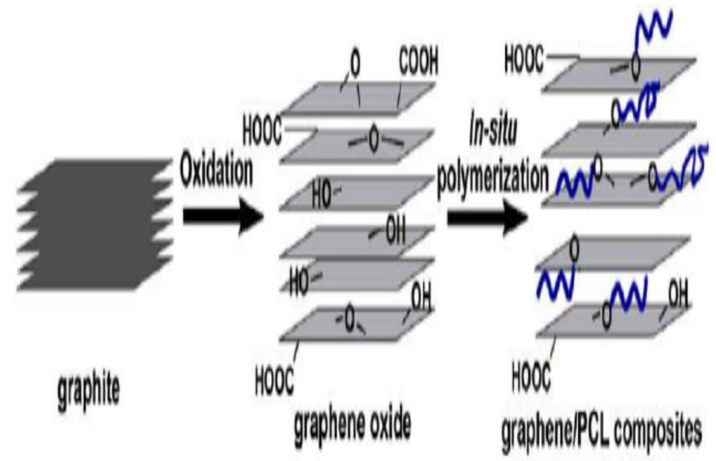

Figure 2. Grafting of $\mathrm{PCl}$ onto graphene sheets via in-situ polymerization of $\mathrm{PCl}$. hydrochloride (EDC), N-hydroxysuccinimide (NHS), Methanol, dichloromethane, (3-aminopropyl)triethoxysilane $99 \%$, tin 2-ethylhexanoate $(95 \%)$, polycaprolactone $(\mathrm{PCl})$ (Mn 80,000), methacrylic anhydride, hydrazine monohydrate (N2H4 64-65\%, reagent grade, 98\%), phosphorus pentoxide $\left(\mathrm{P}_{2} \mathrm{O}_{5}\right)$, DL-lactic acid, (80-85\% aqueous solution), Graphite powder and triethylamine were purchased and used as received. Milli-Q water with a resistivity of $18.2 \mathrm{~m} \Omega \mathrm{cm}-1$ was used in all preparations.

\subsection{Material synthesis}

\subsubsection{Preparation of graphene oxide and chemically converted graphene}

Stable dispersions of CCG in DMF $\left(0.5 \mathrm{mg} \mathrm{ml}^{-1}\right)$ were prepared by sonicating CCG flakes, first synthesised from GO, in DMF (Figure 3 and Figure 4) using the procedure developed by Dr. Gambhir. GO was produced from natural graphite powder using a modified Hummers' method and then the $\mathrm{GO}$ was reduced to $\mathrm{CCG}$ using hydrazine $\left(\mathrm{NH}_{2} \mathrm{NH}_{2}\right)$ following Dan $\delta$ i's method. The aqueous CCG dispersion was further reduced using excess quantities of hydrazine followed by acidification to agglomerate and precipitate the CCG flakes from the aqueous dispersion. In the next step, the CCG flakes were filtered, washed and dried to give graphene powder. The dry graphene powder was then added to DMF followed by addition of triethylamine $\left(\mathrm{N}\left(\mathrm{CH}_{2} \mathrm{H}_{5}\right)_{3}\right)$, that helps the homogenous dispersion of $\mathrm{CCG}$, and the mixture was sonicated with continuous cooling under a dry nitrogen purge for up to 5 hours. The procedure resulted in a stable homogeneous dispersion of CCG in DMF with a CCG concentration of $0.5 \mathrm{mg} \mathrm{ml}^{-1}$.

\subsubsection{Preparation of graphene/PCI composites through mixing and covalent attachment method}

In this section, we investigated the possibility of developing graphene/ $\mathrm{PCl}$ composites using two approaches, the mixing method and the covalent attachment method. The composites were prepared with different graphene contents that are $0.1,0.5,1,5$ and $10 \mathrm{wt} . \%$. The composites are labelled according to their preparation method and the

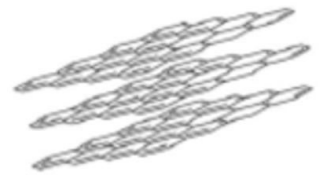

Graphite

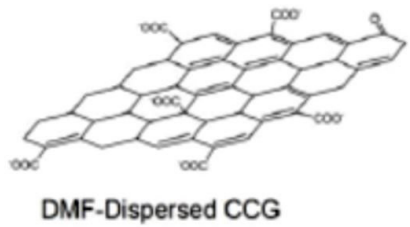

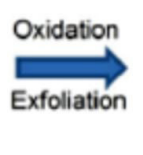
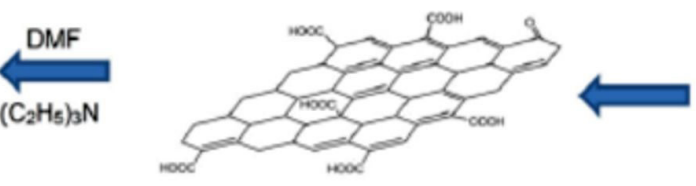

CCG (Powder)
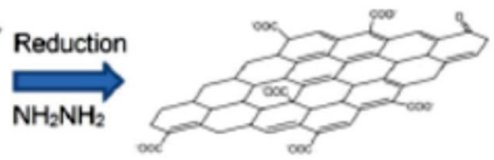

GO

CCG (Aqueous)

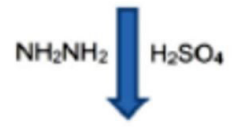

Filteration

Washing

Drying

Figure 3. Synthesis of DMF-disperse CCG. 


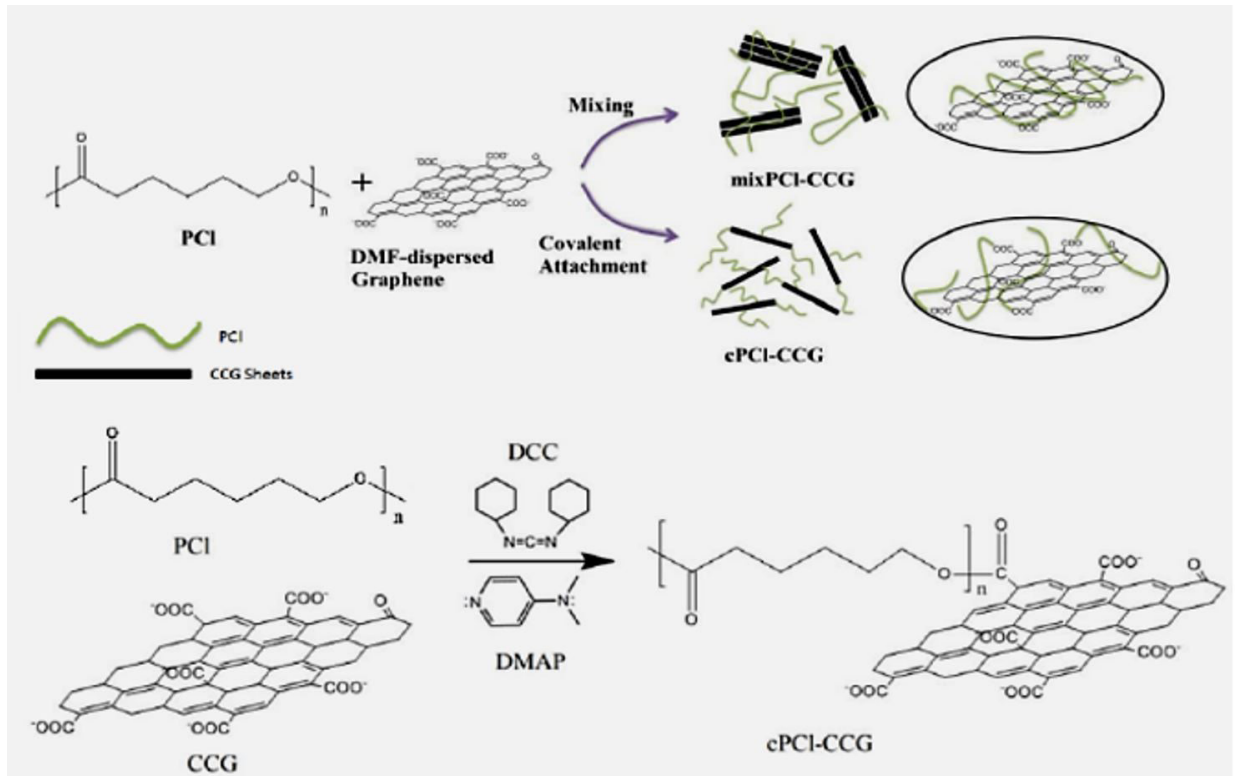

Figure 4. Preparation of PCl-CCG composites through mixing and covalent attachment methods.

weight percentage of their graphene content. All prepared samples are listed in Table 1. The labels mixPCl-CCG $x \%$ and $\mathrm{cPCl}-\mathrm{CCG} x \%$ represent the composites prepared though the mixing and covalent attachment methods respectively. The $x$ is the weight percentage of the graphene content in the composites, e.g. cPCl-CCG $5 \%$ represents the covalently linked composite with $5 \mathrm{wt}$ \% graphene content.

Graphene/PCl binary mixtures (mixPCl-CCGs) were prepared by mixing $\mathrm{PCl}$ in an appropriate amount of a $0.5 \mathrm{mg} \mathrm{ml}-1$ DMF-dispersed graphene at $75{ }^{\circ} \mathrm{C}$ for $3 \mathrm{~h}$, whilst in the preparation of covalently linked graphene/ $\mathrm{PCl}$ composites (cPCl-CCGs) the mixture of PCland graphene was followed by the addition of $N, N^{\prime}$-dicyclohexylcarbodiimide (DCC) as coupling agent and 4-dimethylaminopyridine (DMAP) as catalyst. In the mixing method, no strong link is formed between the graphene sheets and polymer chains, and the graphene sheets are entangled with the polymer chains. On the other hand, in the covalent attachment method, the polymer chains get covalently linked to the peripheral carboxyl groups of the graphene sheets by esterification in the presence of DCC and DMAP.

Covalent linkages between graphene sheets and polymer chains can make the material stronger and even tougher. Addition of polymer to graphene dispersions has always been the main challenge in the process of composite preparation. The polymer should be added to the graphene dispersion slowly to avoid agglomeration and disturbance of the graphene dispersion. The other challenge was to find the optimum matrix/filler ratio. It was immediately apparent that the resulting black graphene/ $\mathrm{PCl}$ composites became less flexible with increasing graphene content. The addition of graphene was found to improve the tensile strength and conductivity of the polymer as found in the characterization sections below, however exceeding $5 \mathrm{wt} . \%$ graphene content made composite too brittle to handle for many of the characterizations. Consequently, no samples were prepared with more than $10 \%$ graphene.
Table 1. PCl samples with different graphene concentrations prepared via mixing and covalent attachment methods.

\begin{tabular}{lcl}
\hline PreparationMethod & $\begin{array}{c}\text { Graphene contents } \\
\text { (Wt. \%) }\end{array}$ & Sample labels \\
\hline Mixed & 0 & PCL \\
& 0.1 & mixCL-CCG 0.1\% \\
& 0.5 & mixCL-CCG 0.5\% \\
& 1 & mixCL-CCG 1\% \\
& 5 & mixCL-CCG 5\% \\
Covalent Attachment & 10 & mixCL-CCG 10\% \\
& 0 & PCL \\
& 0.1 & mixCL-CCG 0.1\% \\
& 0.5 & mixCL-CCG 0.5\% \\
& 1 & mixCL-CCG 1\% \\
& 5 & mixCL-CCG 5\% \\
& 10 & mixCL-CCG 10\% \\
\hline
\end{tabular}

\section{Results and Discussion}

\subsection{Stability and particle size of the dispersions}

A Malvern Zetasizer was used to monitor the stability of aqueous and DMFdispersed CCG dispersions and to measure the particle size of GO, aqueous and DMF-dispersed CCG dispersions. For the experiments, $1 \mathrm{ml}$ of the dispersions was diluted and transferred into a quartz cuvette for Zeta potential test. The zeta potential of the aqueous and DMF-dispersed CCG was found to be $-39 \mathrm{mV}$ and $-31 \mathrm{mV}$ respectively (Figure 5a). The zeta potential for both samples is $<-30 \mathrm{mV}$ and they remain stable for up to 100 days indicating good stability of the dispersions. The average size of the sheets as estimated by Zetasizer in the GO and CCG dispersions is similar, varying between 436 to $464 \mathrm{~nm}$ with the GO dispersion containing slightly larger sheets Figure $5 \mathrm{~b}$. 
The results indicate that the longer sonication time used for dispersing graphenenanosheets in DMF has not affected the average size of graphene sheets in DMF dispersion.

\subsection{SEM images of aqueous and DMF dispersed CCG}

To prepare the SEM samples, one drop of each CCG dispersion was deposited on a silanized silicon wafer and the solvent was evaporated overnight. SEM images show on Figure 6 that both aqueous and DMF-dispersed graphene samples contain graphene sheets in different sizes. The dispersions contain very small graphene sheets $(<100 \mathrm{~nm})$ due to fragmentation occurring during sonication. The size of the larger sheets varies between 100 to $500 \mathrm{~nm}$.

\subsection{X-ray Diffraction}

$\mathrm{X}$-ray Diffraction (XRD) is a useful technique to obtain information about the structure, crystallinity, orientation of crystallites and phase composition in crystalline and semi-crystalline materials. The peaks in an XRD pattern correspond to diffractions from the crystallographic planes, by which the interplanar distances of the crystalline material can be calculated X-ray diffraction (XRD) spectra of graphite GO and DMF-dispersed CCG are illustrated in Figure 7. The samples were prepared either using a powder (graphite) or through depositing $500 \mu \mathrm{l}$ of the relevant dispersion on a quartz substrate, followed by evaporating the solvent at room temperature and the spectra collected Graphite shows a strong peak at around $26.7^{\circ}$ that is typical of well-ordered graphene crystal planes in graphitic systems. This peak corresponds to an interlayer distance (d-spacing) of $3.34 \AA$. After oxidation to $\mathrm{GO}$, the peak in graphite is replaced with a new intense diffraction peak at about $10.6^{\circ}$ (d-spacing of about $8.35 \AA$ ) in GO. The increase in d-spacing of GO is attributed to the intercalation of water molecules between two layers as well as hydrophobic nature of GOAfter chemical reduction, CCG displays a weak and broad $\mathrm{x}$-ray diffraction peak at around $20 \sim 24^{\circ}$, corresponding to a d-spacing of about $3.69 \AA$. The decrease in the average interlayer spacing in the CCG sample is attributed to deoxygenation and reduction in the basal defects of GO The interlayer spacing of the peak in CCG is close to the d-spacing peak value of graphite, but the CCG peak is broad, representing the formation of much more disordered graphene sheets compared to graphite (a)

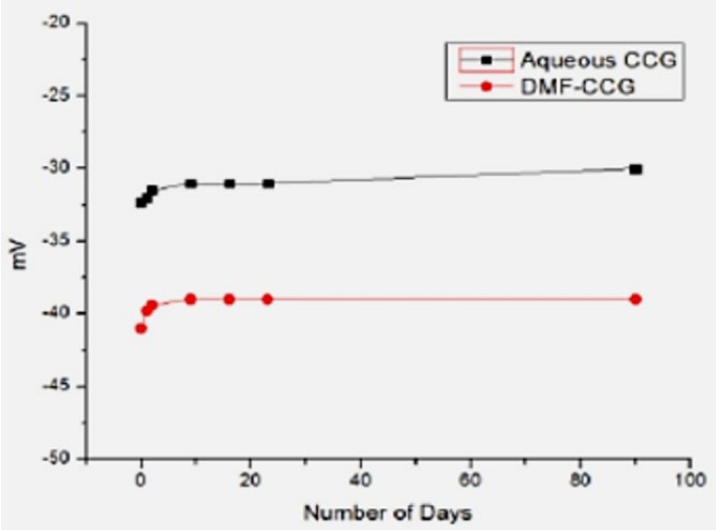

(b)

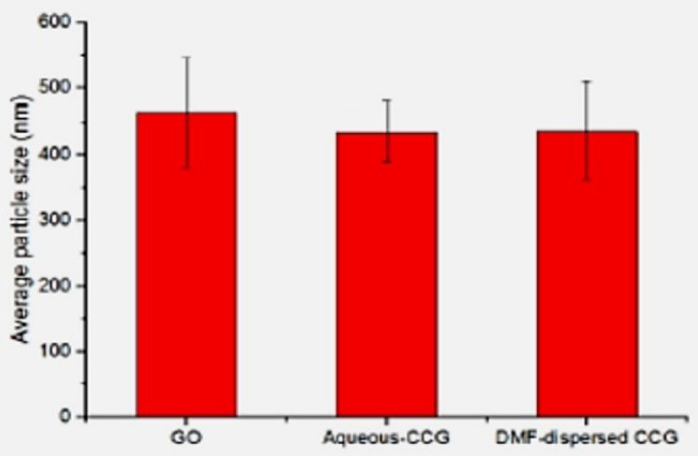

Figure 5. (a) Dispersion stability of CCG samples and (b) average particle size of GO and CCG samples.
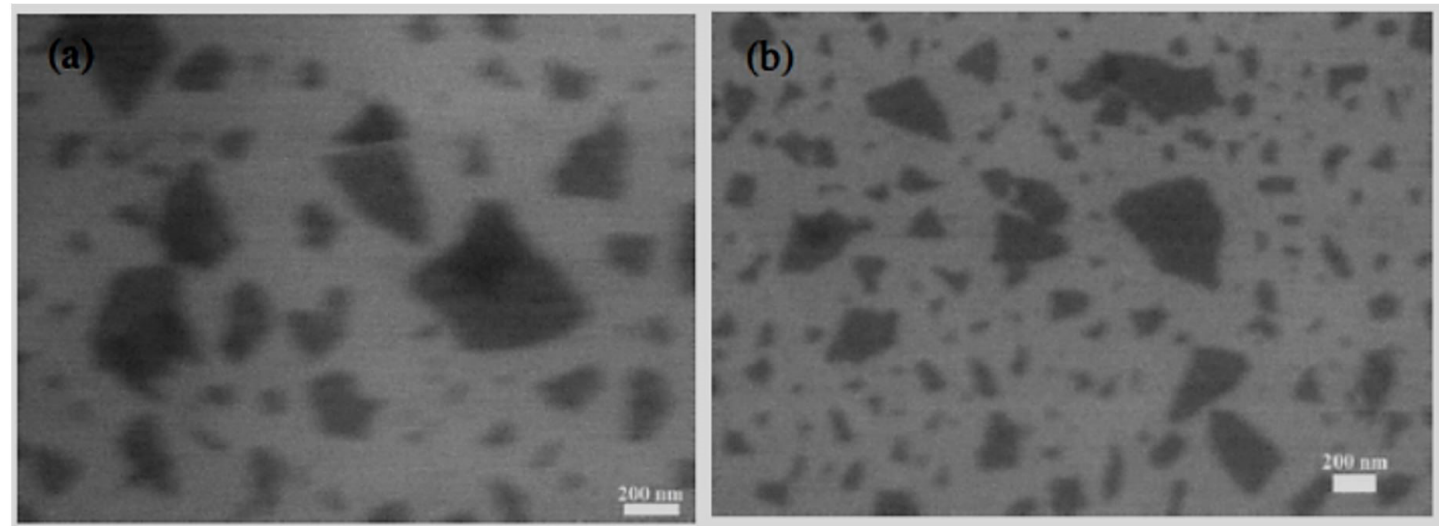

Figure 6. Scanning electron microscopy of (a) aqueous CCG, (b) DMF-dispersed CCG. 


\subsection{Characterization of graphene/PCl composites}

\subsubsection{Thermogravimetric analysis}

TGA was used to help understand the composition of the composites through characterizing the thermal properties of the $\mathrm{PCl}$ and $\mathrm{PCl}-\mathrm{CCG}$ composites. TGA datawere obtained by heating $10 \mathrm{mg}$ of samples to above $900^{\circ} \mathrm{C}$ under nitrogen at a rate of $5^{\circ} \mathrm{C} \mathrm{min}^{-1}$. Figure 8 shows the thermal behaviour of pristine $\mathrm{PCl}$ as well as $\mathrm{cPCl}-\mathrm{CCG}$ and mix PCl-CCG composites with $0.1,0.5,1$ and $5 \mathrm{wt}$. \% graphene contents. Based on the results, the addition of graphene, whether in a binary mixture or a covalently linked composite, has very little effect on the decomposition temperature of polycaprolactone. All samples show thermal stability up to $380{ }^{\circ} \mathrm{C}$ and the decomposing rapid decomposition, which is assigned to the degradation of the polymer chains. The residual weight after full decomposition of the polymer can be assigned to the graphene content as CCG weight losses are minimal in this temperature range.

The graphene percentage calculated from TGA analysis of the Composites prepared by the covalent attachment method (cPCl-CCG) is consistent with the percentage of graphene added to the reaction initially and indicates good Attachment of the polymer. However, the graphene percentage in the mixtures (mixPCl-CCG) is very different to that added to the reaction mixture. This is Consistent with the observation of polymer being washed out of the composite during precipitation.

\subsubsection{Differential scanning calorimetry}

The correlation between the heat flow and the temperatures of the materials can be studied by using differential scanning calorimetry (DSC). DSC test was done on pristine $\mathrm{PCl}$, cPCl-CCG and mixPCl-CCG composites with $0.1,1$ and $5 \mathrm{wt} . \%$ graphene contents. The samples $(5-8 \mathrm{mg})$ were first dried in vacuum oven overnight to remove the solvents residues, and then they were presealed into aluminum pans for the tests. The melting point of $\mathrm{PCl}$ was found to be around $57^{\circ} \mathrm{C}$. DSC curves showed that the addition of graphene to polycaprolactone either covalently or as a mixture did not significantly affect the melting point of the $\mathrm{PCl}$ composites, which remains at $55-60^{\circ} \mathrm{C}$ (Figure 9). Addition of graphene was found to have increasing effect on the crystallization temperature for all of the composites. On addition of just $0.1 \mathrm{wt} . \%$ graphene the crystallization point increases massively from $19{ }^{\circ} \mathrm{C}$ in pristine $\mathrm{PCl}$ to $33^{\circ} \mathrm{C}$. This phenomenon can

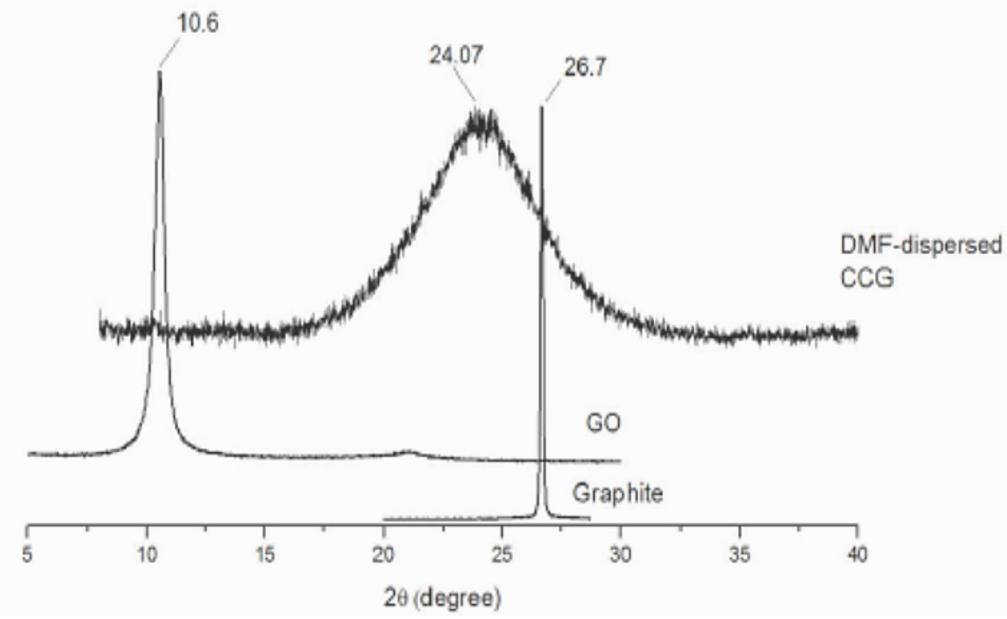

Figure 7. X-ray diffraction patterns of graphite, GO and DMF-dispersed CCG.

(a)

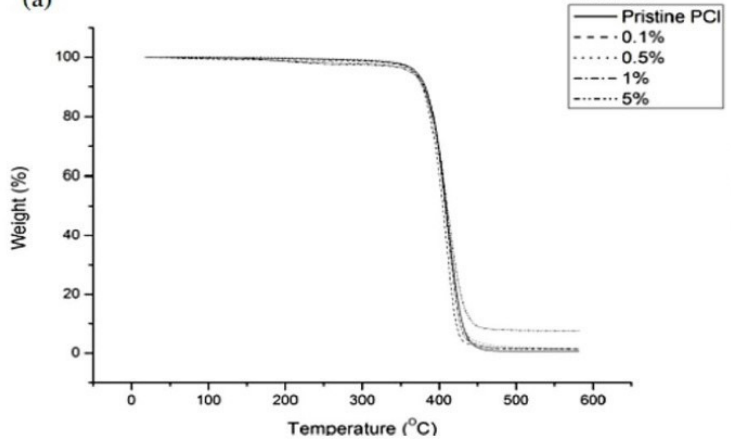

(b)

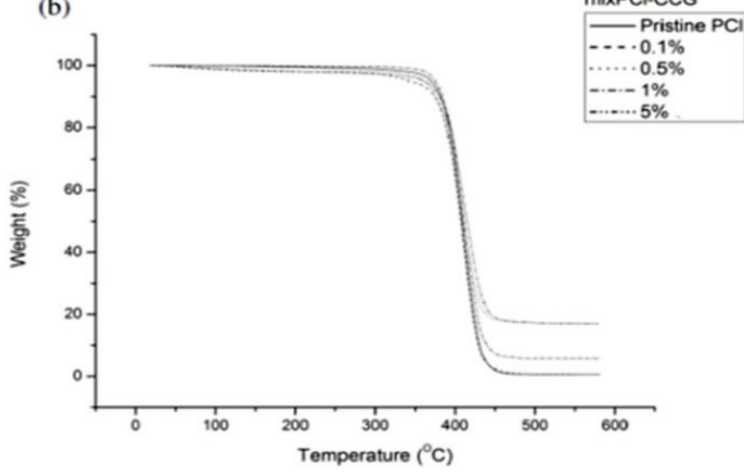

Figure 8. Thermogravimetric curves of (a) cPCl-CCG and (b) mixPCl-CCG composites with different graphene contents. The residual weight after full decomposition of the polymer represents the actual amount of graphene in composites. 
be attributed to the nucleating effect of graphene on $\mathrm{PCl}$ crystallization. Increasing the addition of graphene further increases the crystallization temperature and broadens the crystalization peak, indicating confined mobility of polymer chains and suppression of the crystal structure in

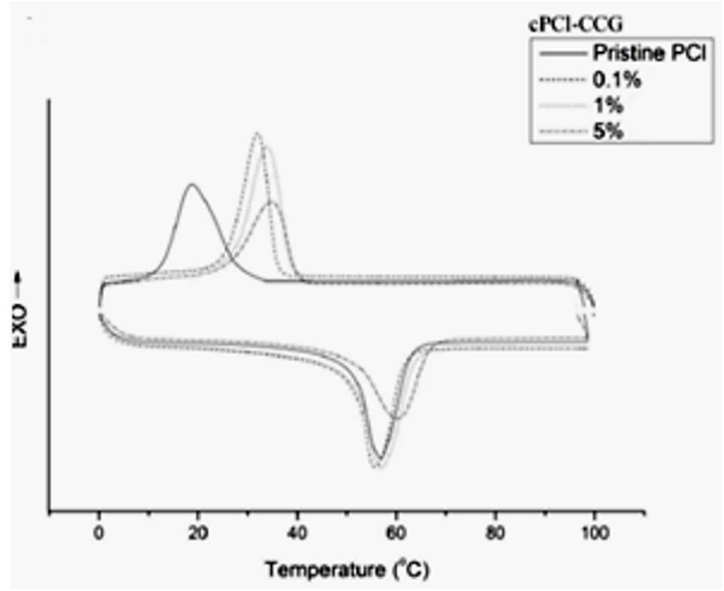

Figure 9. Differential scanning calorimetry curve of $\mathrm{cPCl}-\mathrm{CCG}$ composites. The addition of graphene generally has little effect on the melt temperature, but increases the crystallization temperature of the composites. the composite. The crystallization temperature reaches $35^{\circ} \mathrm{C}$ in $\mathrm{PCl}$ composites with 5 wt. \% graphenecontent.

\subsubsection{Mechanical properties}

Tensile testing was performed to investigate the effect of $\mathrm{CCG}$ on the mechanical properties of $\mathrm{PCl}$. Typical stress-strain curves of $\mathrm{PCl}$ and $\mathrm{PCl}$ composites are shown in Figure 10, and the detailed data of the mechanical properties are listed in Table 2. To prepare samples for mechanical properties tests, the samples were hot pressed at $100{ }^{\circ} \mathrm{C}$ to obtain a $0.1 \mathrm{~mm}$ thick film. Then the film was cut into strips with a width of $3 \mathrm{~mm}$ and a length of $20 \mathrm{~mm}$. Pure $\mathrm{PCl}$ shows the typical stress-strain curves of ductile materials started with linear deformation behaviour up to the yield point, which is considered the upper limit of elasticity, followed by a plastic response that is irreversible.

The addition of graphene has not changed the ductility of the composites even at higher graphene contents, indicating a good level of graphene dispersion in the polymer matrix even in the composites prepared by mixing method. The pure $\mathrm{PCl}$ showed a high strain at break up to $1200 \%$, but had low tensile yield strength and Young's modulus of around $10 \mathrm{MPa}$ and $94 \mathrm{MPa}$ respectively. In general, the addition of graphene improves the strength of the composites, but decreases the elongation at break as the interaction between graphene and the matrix restricts the movement of the polymer chains. Figure 10 shows the increase in tensile (a)

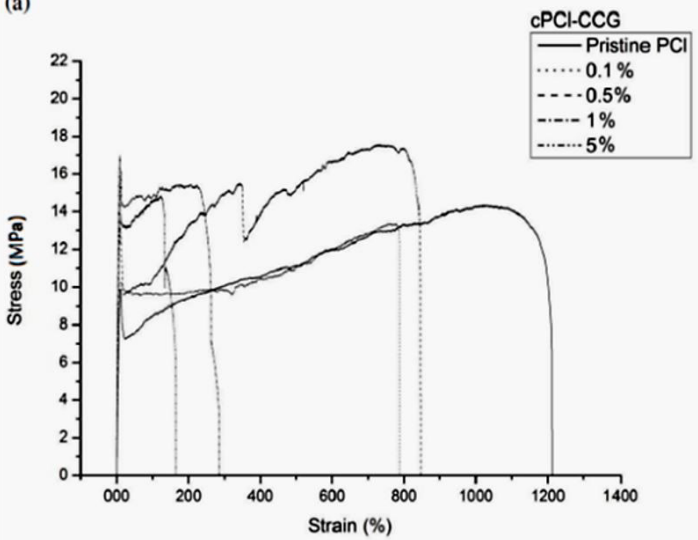

(b)

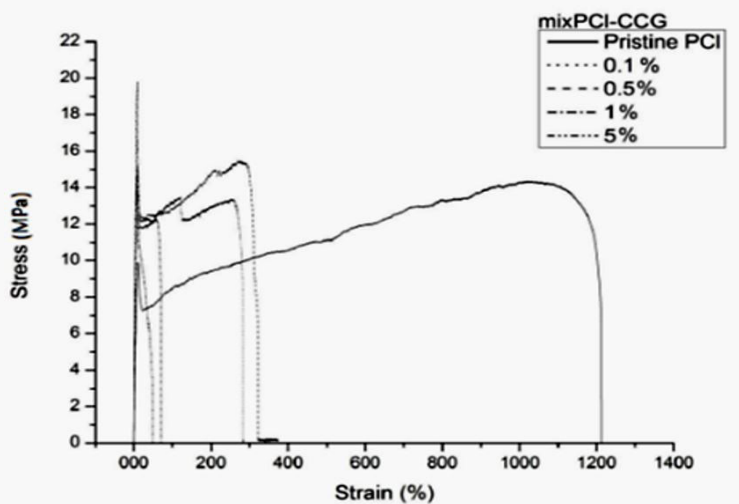

Figure 10. Stress-Strain curves of (a) cPCl-CCG and (b) mixPCl-CCG composites showing the large increase in tensile strengths and reductions in elongation at break.

Table 2. Mechanical properties of PCl, covalently-linked cPCl-CCG and mixPCl- CCG.

\begin{tabular}{lcccc}
\hline $\begin{array}{c}\text { Preparation } \\
\text { Method }\end{array}$ & $\begin{array}{c}\text { Graphene } \\
\text { Contents(wt.\%) }\end{array}$ & $\begin{array}{c}\text { Tensile Yield } \\
\text { (Mpa) }\end{array}$ & $\begin{array}{c}\text { Youngs Modulus } \\
\text { (Mpa) }\end{array}$ & $\begin{array}{c}\text { Elongation at Break } \\
\text { (\%) }\end{array}$ \\
\hline Polycaprolactone & $\mathbf{0}$ & $\mathbf{1 0} \pm \mathbf{0 . 2}$ & $\mathbf{9 4} \pm \mathbf{1 2}$ & $\mathbf{1 2 1 2} \pm \mathbf{8 6}$ \\
Covalent & 0.1 & $10 \pm 0.4$ & $90 \pm 4$ & $842 \pm 57$ \\
& 0.5 & $13 \pm 0.2$ & $199 \pm 14$ & $788 \pm 38$ \\
& 1 & $16 \pm 0.2$ & $236 \pm 6$ & $286 \pm 18$ \\
Mixture & 5 & $17 \pm 0.8$ & $259 \pm 22$ & $166 \pm 12$ \\
& 0.1 & $13.4 \pm 0.3$ & $260 \pm 26$ & $321 \pm 53$ \\
& 0.5 & $14.5 \pm 0.6$ & $219 \pm 12$ & $282 \pm 28$ \\
& 1 & $15 \pm 0.9$ & $277 \pm 23$ & $69.5 \pm 11$ \\
\hline
\end{tabular}


yield strength in both covalently linked and mixed method materials. Incovalently attached composites, the addition of just $0.5 \mathrm{wt}$. \% graphene increased tensile yield stress by almost $30 \%$ and doubled it on addition of $5 \%$. Similarly the Young's modulus increases from $94 \mathrm{MPa}$ in pristine $\mathrm{PCl}$ to $199 \mathrm{MPa}$ to $259 \mathrm{Mpa}$ across the same range.

\section{Conclusion}

The main aim of this project was to develop biocompatible, processablebiocomposites for biomedical applications. Chemically converted graphene (CCG) as a dispersion (aqueous or DMF-dispersed CCG) was used as the main filler in this work due to its excellent properties and its potential to enhance the mechanical and electrical properties of the polymers. Two approaches were taken to synthesize composites, a mixing method in which the polymer was mixed with the CCG dispersion (mixPCl-CCG) and a covalent attachment method whereby the polymer chains were covalently linked to $\mathrm{CCG}$ sheets (cPCl-CCG). The homogeneous dispersions of $\mathrm{CCG}$ in cPCl-CCG composites led to the development of composites with much better flexibility compared to mixPCl-CCG samples. The addition of $0.5 \mathrm{wt} . \%$ CCG increased the tensile strength and Young's modulus by more than $70 \%$ and $170 \%$ respectively. The conductivity of $\mathrm{PCl}$ was also improved by around 12 orders of magnitude on addition of 5 wt. \% CCG in mixPCl- CCG composites.

\section{References}

1. Williams, D. F. (1999). The Williams dictionary of biomaterials. USA: Liverpool University Press.

2. Guo, B., Glavas, L., \& Albertsson, A. C. (2013). Biodegradable and electrically conducting polymers for biomedical applications. Progress in Polymer Science, 38(9), 1263-1286. http://dx.doi. org/10.1016/j.progpolymsci.2013.06.003.

3. Hull, D., \& Clyne, T. W. (1996). An introduction to composite materials. USA: Cambridge University Press. http://dx.doi. org/10.1017/CBO9781139170130.

4. Nair, L. S., \& Laurencin, C. T. (2006). Polymers as biomaterials for tissue engineering and controlled drug delivery. In K. Lee $\&$ D. Kaplan (Eds.), Tissue engineering $i$ : scaffold systems for tissue engineering (pp. 47-90). New York: Springer-Verlag Berlin Heidelberg. http://dx.doi.org/10.1007/b137240.

5. Barbucci, R. (2002). Integrated biomaterials science. USA: Springer. http://dx.doi.org/10.1007/b112196.

6. Tian, H. Y., Tang, Z. H., Zhuang, X. L., Chen, X. S., \& Jing, X. B. (2012). Biodegradable synthetic polymers: preparation, functionaliztion and biomedical application. Progress in Polymer Science, 37(2), 237-280. http://dx.doi.org/10.1016/j. progpolymsci.2011.06.004.

7. Schuerch, C. (1972). The chemical synthesis and properties of polysaccharides of biomedical interestIn: Fortschritte der Hochpolymeren-Forschung. In G. Leone \& R. Barbucci. Advances in polymer science (pp. 173-194). Berlin: Springer. http://dx.doi.org/10.1007/3-540-05838-9_12.

8. Khan, F., \& Ahmad, S. R. (2013). Polysaccharides and their derivatives for versatile tissue engineering application. Macromolecular Bioscience, 13(4), 395-421. http://dx.doi. org/10.1002/mabi.201200409. PMid:23512290.

9. Li, Z., Leung, M., Hopper, R., Ellenbogen, R., \& Zhang, M. (2010). Feeder - free self-renewal of human embryonic stem cells in 3D porous natural polymer scaffolds. Biomaterials, 31(3),
404-412. http://dx.doi.org/10.1016/j.biomaterials.2009.09.070. PMid:19819007.

10. Lindblad, M. S., Sjöberg, J., Albertsson, A.-C., \& Hartman, J. (2007). Hydrogels from polysaccharides for biomedical applications. In D. S. Argyropoulos. Materials, chemicals, and energy from forest biomass (pp. 153-167). Washington: American Chemical Society. http://dx.doi.org/10.1021/bk2007-0954.ch010

11. Leone, G., \& Barbucci, R. (2009). Polysaccharide based hydrogels for biomedical applications. In R. Obarbucci (Ed.), Hydrogels (pp. 25-41). Milan: Springer.

12. Kontio, R., Ruuttila, P., Lindroos, L., Suuronen, R., Salo, A., Lindqvist, C., Virtanen, I., \& Konttinen, Y. T. (2005). Biodegradable polydioxanone and poly $(\mathrm{L} / \mathrm{D})$ lactide implants: an experimental study on peri-implant tissue response. International Journal of Oral and Maxillofacial Surgery, 34(7), 766-776. http://dx.doi. org/10.1016/j.ijom.2005.04.027. PMid:15979853.

13. Ulery, B. D., Nair, L. S., \& Laurencin, C. T. (2011). Biomedical applications of biodegradable polymers. Journal of Polymer Science. Part B, Polymer Physics, 49(12), 832-864. http:// dx.doi.org/10.1002/polb.22259. PMid:21769165.

14. Sinha, V. R., Bansal, K., Kaushik, R., Kumria, R., \& Trehan, A. (2004). Poly-€-caprolactone microspheres and nanospheres: an overview. International Journal of Pharmaceutics, 278(1), 1-23. http://dx.doi.org/10.1016/j.ijpharm.2004.01.044. PMid: 15158945

15. Mohanty, A. K., Misra, M., \& Hinrichsen, G. (2000). Biofibres, biodegradable polymers and biocomposites: An overveiw. Macromolecular Materials and Engineering, 276-277(1), 1-24. http://dx.doi.org/10.1002/(SICI)14392054(20000301)276:1<1::AID-MAME1>3.0.CO;2-W.

16. Mani, R., Tang, J., \& Bhattacharya, M. (1998). Synthesis and characterization of starchgraft-polycaprolactone as compatibilizer for starch/ polycaprolactone blends. Macromolecular Rapid Communications, 19(6), 283-286. http://dx.doi.org/10.1002/ (SICI)1521-3927.

17. Chiacchiarelli, L. M., Monsalve, L., Vázquez, A., Kenny, J. M., \& Torre, L. (2014). A polycaprolactone - based compatobolozation treatment to improve dispersion and interphase structure of silica polyurethane composites. Polymer Engineering and Science, 54(8), 1817-1826. http://dx.doi.org/10.1002/pen.23723.

18. Chavalitpanya, K., \& Phattanarudee, S. (2013). Poly(Lactic acid)/ Polycaprolactone blends compatibilized with block copolymer. Energy Procedia, 34, 542-548. http://dx.doi. org/10.1016/j.egypro.2013.06.783.

19. Hull, D., \& Clyne, T. W. (1996). An introduction to composite materials. Cambridge: Cambridge University Press. http:// dx.doi.org/10.1017/CBO9781139170130.

20. Tjong, S. C. (2012). Polymer composites with carbonaceous nanofillers: properties and applications. USA: Wiley Publications. http://dx.doi.org/10.1002/9783527648726.

21. Gaharwar, A. K., Sant, S., Hancock, M. J., \& Hacking, S. A. (2013). Nanomaterials in tissue engineering: fabrication and applications. UK: Woodhead Publishing. http://dx.doi. org/10.1533/9780857097231.

22. Neto, A. C., Guinea, F., \& Peres, N. M. R. (2006). Drawing conclusions from graphene. Physics World, 19(11), 33-37. http://dx.doi.org/10.1088/2058-7058/19/11/34.

23. Kasuga, T., Ota, Y., Nogami, M., \& Abe, Y. (2000). Preparation and mechanical properties of polulactic acid composites containing hydroxyapatite fibers. Biomaterials, 22(1), 19-23. http://dx.doi. org/10.1016/S0142-9612(00)00091-0. PMid:11085379.

24. Hong, Z., Zhang, P., He, C., Qiu, X., Liu, A., Chen, L., Chen, X., \& Jing, X. (2005). Nano composite of poly(L-lactide) and surface grafted hydroxyapatite: mechanical properties and 
biocompatibility. Biomaterials, 26(32), 6296-6304. http://dx.doi. org/10.1016/j.biomaterials.2005.04.018. PMid:15913758.

25. Lee, K. W., Wang, S. F., Yaszemski, M. J., \& Lu, L. C. (2008). Physical Properties and cellular responses to crosslinkablepoly(propylene fumarate)/hydroxyapatite nanocomposites. Biomaterials, 29(19), 2839-2848. http://dx.doi. org/10.1016/j.biomaterials.2008.03.030. PMid:18403013.

26. Ramalingam, M., Vallittu, P., Ripamonti, U., \& Li, W. J. (2012). Tissue engineering and regenerative medicine: a nano approach. Florida: CRC Press. http://dx.doi.org/10.1201/b13049.

27. Li, X., Wang, L., Fan, Y., Feng, Q., Cui, F.-Z., \& Watari, F. (2013). Nanostructured scaffolds for bone tissue engineering. Journal of Biomedical Materials Research. Part A, 101A(8), 2424-2435. http://dx.doi.org/10.1002/jbm.a.34539. PMid:23377988.

28. Ray, S. S., Yamada, K., Okamoto, M., \& Ueda, K. (2002). Polylactide-layered silicate nanocomposite: a novel biodegradable material. Nano Letters, 2(10), 1093-1096. http://dx.doi. org/10.1021/n10202152.

29. Krikorian, V., \& Pochan, D. J. (2003). Poly(L-Lactic acid)/ layered silicate nanocomposite: fabrication, characterization, and properties. Chemistry of Materials, 15(22), 4317-4324. http://dx.doi.org/10.1021/cm034369+.

30. Lee, J. H., Park, T. G., Park, H. S., Lee, D. S., Lee, Y. K., Yoon, S. C., \& Nam, J.-D. (2003). Thermal and mechanical characteristics of poly(L-Lactic acid) nanocomposite scaffold.
Biomaterials, 24(16), 2773-2778. http://dx.doi.org/10.1016/ S0142-9612(03)00080-2. PMid:12711524.

31. Singh, V., Joung, D., Zhai, L., Das, S., Khondaker, S. I., \& Seal, S. (2011). Graphene based materials: past, present and future. Progress in Materials Science, 56(8), 1178-1271. http:// dx.doi.org/10.1016/j.pmatsci.2011.03.003.

32. Green, A. A., \& Hersam, M. C. (2009). Solution phase production of graphene with controlled thickness via density differentiation. Nano Letters, 9(12), 4031-4036. http://dx.doi. org/10.1021/n1902200b. PMid:19780528.

33. Wintterlin, J., \& Bocquet, M. L. (2009). Graphene on metal surfaces. Surface Science, 603(10-12), 1841-1852. http:// dx.doi.org/10.1016/j.susc.2008.08.037.

34. Park, S., \& Ruoff, R. S. (2009). Chemical methods for the production of graphenes. Nature Nanotechnology, 4(4), 217224. http://dx.doi.org/10.1038/nnano.2009.58. PMid:19350030.

35. Wang, R. J., Wang, X. H., Chen, S. J., \& Jiang, G. H. (2012). In situ polymerization approach to poly(e-caprolactone)-Graphene oxide composites. DesignedMonomersandPolymers, 15(3), 303-310. http://dx.doi.org/10.1163/156855511X615696.

Received: June 04, 2018

Revised: Sept. 13, 2018

Accepted: Dec. 10, 2018 